\title{
Consumer perception versus scientific evidence about health benefits and safety risks from fish consumption
}

\author{
Wim Verbeke ${ }^{1, *}$, Isabelle Sioen ${ }^{2,3}$, Zuzanna Pieniak ${ }^{1}$, John Van Camp ${ }^{2}$ and \\ Stefaan De Henauw ${ }^{3}$ \\ 'Department of Agricultural Economics, Ghent University, Coupure links 653, B-9000 Ghent, Belgium: ${ }^{2}$ Department \\ of Food Safety and Food Quality, Ghent University, Ghent, Belgium: ${ }^{3}$ Department of Public Health, Ghent University, \\ Ghent, Belgium
}

\section{Submitted 20 July 2004: Accepted 8 November 2004}

\begin{abstract}
Objective: To investigate the gap between consumer perception and scientific evidence related to health benefits and safety risks from fish consumption.

Design: Consumer perceptions from a cross-sectional survey in March 2003 in Belgium were compared with scientific evidence based on a literature review.

Method: A quota sampling procedure was used with age as quota control variable. Subjects completed a self-administered questionnaire including health benefit beliefs from fish, fish content and effect beliefs for nutrients and harmful substances.

Subjects: Adults $(n=429)$, who were the main person responsible for food purchasing in the household (284 women; 145 men), aged 18-83 years, from different regional, education, family size and income groups.

Results: Fish is predominantly perceived as a healthy food that reduces risk for coronary heart disease, which corroborates scientific evidence. This perception is stronger among women than among men. In contrast with scientific evidence, $46 \%$ of the consumers believe that fish contains dietary fibre, whereas less than one-third is aware that fish contains omega- 3 fatty acids and that this nutrient has a positive impact on human health. The gap between perception and evidence is larger among consumers with lower education. In general, consumers are better aware of the content and effect of harmful substances than of nutrients in fish.

Conclusions: Despite conclusive evidence about the content and positive effect of omega-3 fatty acids in fish, related consumer awareness and beliefs are poor and often wrong. This study exemplifies the need for nutrition education and more effective communication about the health benefits of fish consumption.
\end{abstract}

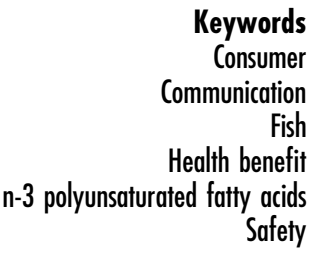

Over past decades, nutritional research has identified a number of food groups that are recommended to take a prominent position in the human diet on the basis of their potential beneficial effect on chronic degenerative diseases. One such food group is the group of marine animal products, which are recognised in general terms for their content of proteins with high biological value, their low content of saturated fat and the presence of certain minerals and vitamins. In relation to other foods, marine foods represent a very important source of vitamin $\mathrm{D}^{1,2}$, which is essential for proper bone mineralisation. Perhaps most importantly, fish represents a unique source of longchain polyunsaturated fatty acids (PUFA) of the $n-3$ family (colloquially, omega-3 fatty acids), mainly eicosapentaenoic acid and docosahexaenoic acid (DHA), which play an essential role in human health ${ }^{3,4}$. Several studies indicate that fish is also perceived as a healthy food by consumers ${ }^{5,6}$, particularly compared with meat - the main substitute source of protein. Nevertheless, dietary recommendations of eating two portions of fish a week, of which one should be fatty fish, are not met by large groups of the population in many countries ${ }^{7,8}$.

One of the potential barriers to eating fish more frequently ${ }^{9-11}$ may pertain to safety risks. Recently, the perception of fish as healthy food has been troubled by less favourable information regarding safety risks, more specifically the potential adverse health impact of chemical contamination in wild fish. Fish is a major source of human exposure to contaminants such as methyl mercury, polychlorinated biphenyls (PCBs), dioxins, organochlorine pesticides and other environmental contaminants $^{12,13}$. Recent research has for instance indicated that fish is the major source of exposure to dioxin-like substances via food in the Belgian population $^{14}$. The health risks related to the consumption of contaminated fish can be due to carcinogenic contaminants (e.g. PCBs and dioxins), on the one hand, and to the very toxicological characteristics of some heavy metals 
(e.g. arsenic, mercury and cadmium), on the other. Apart from the intrinsic toxicological effects, the hypothesis arises that methyl mercury can diminish the beneficial health effect of the $n-3$ PUFA in fish ${ }^{3,12,13}$.

The psychological impact of information provision about food health risks depends mainly on consumer trust in the information source, perception of hazard characteristics, informational content and presentation format ${ }^{15,16}$. Whereas food risk perception in the strict sense is well-documented, little is known about the balance of safety risks and health benefits in consumers' food choice $^{17,18}$. Studies on communication effectiveness and information processing have shown that adverse messages or negative press related to food health issues can heavily influence consumers' food consumption decisions ${ }^{19-21}$. In this respect, it has been indicated that unfavourable news weighs five to seven times more heavily in consumer decisions than favourable news ${ }^{22,23}$. The overall picture in the case of fish consumption forms the basis for potential conflict models of communicating scientific facts related to dietary recommendations and toxicological food safety assurance. Mass-media information about pollution and contamination of fish can have an impact on consumers' perception and attitude with respect to the incorporation of fish in their diet. At the same time, it can interfere with communication on the health aspects of fish. As a result, consumers may face difficulties in balancing eventual risks with potential health benefits and in making behavioural changes. The conflict model represents also a serious challenge for authorities in the fields of public health, food and nutrition policy.

The objective of the present paper is to investigate the potential gap between scientific evidence versus consumer perception related to fish consumption benefits and risks. First, methods and results from empirical consumer research about fish perception are reported. Next, consumer perception of fish healthiness and safety is compared with evidence-based facts. This comparison may reveal important gaps in public understanding and points on which authorities in the domain of public health, food and nutrition policy have to focus in formulating future fish consumption advice.

\section{Methods}

\section{Study design and subjects}

Survey data were collected through questionnaires in Belgium during March 2003. Subjects were personally contacted and asked to complete a self-administered anonymous questionnaire. The total sample consisted of 429 subjects. The sample was composed of 284 women (66.2\%) and 145 men (33.8\%). This gender distribution reflects the criterion that each respondent was the main person responsible for food purchasing within the household. A quota sampling procedure with age as the main quota control variable was applied. Respondents were recruited in shopping streets, at supermarkets or at home during a door-by-door walking route procedure, until the envisaged age quotas were met. The sample covers a wide range of consumers in terms of sociodemographic characteristics such as education, income, family size, presence of children and region (coastal versus inland) (Table 1). The age of the respondents ranged from 18 to 83 years, with a mean of 40.63 years (standard deviation 14.98 years). A small over-sampling of younger respondents $(<25$ years $)$ compared with the population occurred. The presence of children in the household closely matches the distribution within the Belgian population, whereas average family size in the sample is somewhat higher compared with the population average ${ }^{24}$.

\section{External validity}

The non-probability sampling and respondent recruitment procedure do not strictly yield a statistically representative sample of the Belgian population. Therefore, external validity was checked through comparison of the behavioural characteristics of our sample with those obtained recently by other sources. First, based on a statistically representative sample of 4100 respondents, the Belgian Scientific Institute of Public Health in their 2001 Health Interview Survey reported that $55.6 \%$ of the population consumes fish once a week or more ${ }^{25}$. Second, a share of $52.0 \%$ of a representative consumer sample consumed fish at least once a week in $2002^{26}$. The equivalent number obtained in our study amounts to $56.9 \%$, which matches very closely with data available from previous sources.

Table 1 Sample characteristics $(\%, n=429)$

\begin{tabular}{lc}
\hline Gender & \\
Male & 33.1 \\
Female & 66.9 \\
Age (years) & \\
$\leq 25$ & 21.9 \\
$26-35$ & 17.5 \\
$36-45$ & 22.9 \\
$46-55$ & 22.9 \\
$>55$ & 14.9 \\
Mean (standard deviation) & $40.6(15.0)$ \\
Family size & \\
1 or 2 persons & 48.5 \\
3 or 4 persons & 38.0 \\
5 or more persons & 11.9 \\
Children in the household & \\
Yes & 57.3 \\
No & 42.7 \\
Net income (€ per month) & \\
$\quad<850$ & 5.9 \\
$850-1700$ & 25.6 \\
$1700-2550$ & 36.4 \\
$>2550$ & 32.1 \\
Education & \\
$\quad \leq 18$ years & 32.6 \\
$>18$ years & 67.4 \\
\hline
\end{tabular}




\section{Questionnaire}

First, general consumer perception of fish as being nutritious, healthy and safe was measured on a 5-point interval scale ranging from 'totally not agree' over 'neutral' to 'totally agree'. Second, consumer beliefs of potential health benefits from consuming fish were assessed. Three groups of scientific evidence-based health benefits were included. Based on the evidence that fish contains vitamin $\mathrm{D}$, which is essential for bone mineralisation, the statements that regular fish consumption 'improves bone development' and 'makes people strong' were included. Three statements were included based on fish's content of omega- 3 fatty acids and its potential beneficial role in the prevention of coronary heart disease and certain cancers: 'reduces risk for coronary heart disease', 'reduces risk for certain cancers' and 'prolongs people's life'. Finally, given the presence of DHA in fish and its potential role in brain development, consumer's beliefs in the statements 'stimulates brain development' and 'makes people smart' were measured. Note that benefits were included with both scientific and lay formulations. Third, consumers were probed about their knowledge of nutrients and contaminants in fish. They were asked whether they believe that fish contains vitamin $\mathrm{D}$, omega-3 fatty acids and dietary fibre. Similarly, consumers were asked whether they believe that fish contains PCBs and dioxins, pesticide and other residues, heavy metals, medicinal residues and colorants as potential harmful substances. Consumers were also asked to indicate the perceived effect of these components on human health in terms of 'negative', 'neutral', 'positive' and 'don't know'.

\section{Statistical analyses}

Data were analysed using SPSS 11.01 (SPSS Inc., Chicago, IL, USA). Mean scores and standard deviations on 5-point scales, as well as frequency distributions in re-coded categories (strongly disagree and disagree; agree and strongly agree), are presented in table format. Bivariate analyses through correlation and comparison of mean scores, i.e. independent samples $t$-tests and analysis of variance $F$-tests with Tukey post hoc comparison of mean scores, were used to detect differences in consumer beliefs and perception between different sociodemographic and behavioural consumer groups.

\section{Results}

\section{Behavioural sample characteristics}

Behavioural characteristics included in the analyses are fish consumption frequency, total fish consumption and fish choice in restaurants. In the sample, 56.9\% of the respondents consumed fish once or several times per week; hereafter referred to as 'heavy users'. Most of the fish consumers ate cod (92.0\%), salmon (88.5\%), tuna (68.5\%) and tongue (68.4\%). The least consumed fish species were haddock (17.4\%), brill (23.6\%) and sprat
(25.9\%). There was a tendency for higher percentage of women to eat fish weekly or more compared with men ( $F=3.104 ; P=0.076)$. Furthermore, women declared to choose fish in the restaurant 5.4 times (average on 10) compared with 3.9 times for men $(P<0.001)$. Respondents aged $>40$ years scored significantly higher $(P<0.001)$ for fish consumption frequency compared with younger age groups. Young respondents $(<25$ years $)$ consumed significantly $(P<0.001)$ less fish when visiting restaurants than did older consumers. Respondents with children reported a significantly higher frequency of fish consumption compared with families without children $(P<0.001)$. However, a significantly lower fish consumption frequency was found for respondents whose children were younger than 18 years. A tendency was seen for respondents with the lowest income level (net monthly household income $<850 €$ ) to report a lower frequency for total fish consumption, in comparison with other income groups $(P=0.081)$. Respondents from the lowest income group also chose fish in the restaurant significantly less often $(P=0.002)$. No significant impact of family size and education on behavioural characteristics was noticed.

\section{General beliefs about fish}

Consumers had a very strong belief that fish is healthy and nutritious (Table 2). Women scored higher in the perception that 'fish is healthy' than men $(P=0.003)$. The perception of fish as a healthy food increased with increasing age (correlation coefficient $r=0.218$; $P<0.01$ ), being also higher among respondents with children $(P<0.001)$ and among respondents with lower education $(P=0.041)$. Heavy users of fish had a stronger belief $(P=0.001)$ that fish is healthy than did low users. More doubts were expressed with respect to fish safety. Specifically, about one-fifth of the subjects claimed that fish is unsafe. Young respondents $(<25$ years) in particular perceived fish as less safe compared with other age groups. Furthermore, perception of fish as safe tended to be stronger among families with children $(P=0.069)$. No further sociodemographic differences in fish safety perception were found.

\section{Health benefit beliefs from regular fish consumption}

Table 2 shows that respondents held the strongest belief that regular fish consumption reduces risks for coronary heart disease $(\mu=3.83)$. In contrast, relatively low to neutral scored beliefs were that regular fish consumption makes people smart $(\mu=2.52)$, strong $(\mu=2.95)$ and prolongs life $(\mu=2.98)$. Except for the statement relating to coronary heart disease, about half of the respondents scored neutral for health benefit beliefs, which reflects doubts or uncertainty at the level of consumers. Women had a significantly stronger $(P=0.013)$ belief that regular fish consumption reduces risks of coronary heart disease. This belief was also higher among respondents with 
Table 2 Consumer beliefs about fish $(\%, n=429)$, mean score and standard deviation (SD) on 5-point scale*

\begin{tabular}{|c|c|c|c|c|c|}
\hline Item & Strongly disagree/disagree* & Neutral & Agree/strongly agree* $^{\star}$ & Mean & SD \\
\hline \multicolumn{6}{|l|}{ General beliefs about fish } \\
\hline Fish is nutritious & 1.9 & 17.8 & 80.3 & 3.95 & 0.67 \\
\hline Fish is healthy & 3.1 & 18.4 & 78.5 & 3.98 & 0.76 \\
\hline Fish is safe & 18.4 & 59.1 & 22.5 & 3.06 & 0.74 \\
\hline \multicolumn{6}{|l|}{ Health benefit beliefs } \\
\hline \multicolumn{6}{|l|}{ 'Regular fish consumption...' } \\
\hline Reduces risk for coronary heart disease & 4.0 & 23.0 & 73.0 & 3.83 & 0.75 \\
\hline Reduces risks for certain cancers & 12.8 & 47.9 & 39.3 & 3.29 & 0.81 \\
\hline Prolongs your life & 22.3 & 55.9 & 21.8 & 2.98 & 0.81 \\
\hline Improves bone development & 10.9 & 56.0 & 33.1 & 3.22 & 0.76 \\
\hline Makes people strong & 22.3 & 59.5 & 18.3 & 2.95 & 0.73 \\
\hline Stimulates brain development & 12.1 & 51.3 & 36.6 & 3.29 & 0.82 \\
\hline Makes people smart & 44.8 & 46.0 & 9.2 & 2.52 & 0.89 \\
\hline \multicolumn{6}{|l|}{ Fish content beliefs } \\
\hline \multicolumn{6}{|l|}{ 'Fish contains...' } \\
\hline Vitamin D & 4.6 & 42.1 & 53.3 & 3.65 & 0.82 \\
\hline Omega-3 fatty acids (PUFA) & 6.3 & 61.9 & 31.8 & 3.37 & 0.79 \\
\hline Dietary fibre & 17.1 & 37.4 & 45.5 & 3.35 & 1.01 \\
\hline PCBs & 18.8 & 50.6 & 30.6 & 3.16 & 0.82 \\
\hline Dioxins & 22.6 & 48.3 & 29.1 & 3.08 & 0.86 \\
\hline Pesticide and other chemical residues & 28.4 & 46.8 & 24.9 & 2.94 & 0.89 \\
\hline Heavy metals & 12.2 & 42.0 & 45.8 & 3.40 & 0.83 \\
\hline Medicinal residues & 29.3 & 52.0 & 18.7 & 2.87 & 0.83 \\
\hline Colorants & 37.2 & 41.3 & 21.5 & 2.79 & 0.97 \\
\hline
\end{tabular}

PUFA - polyunsaturated fatty acids; PCBs - polychlorinated biphenyls.

*Categories 'strongly disagree' and 'disagree', and 'agree' and 'strongly agree', from the initial 5-point scale have been merged for clarity of presentation; statistical analyses as reported in the text have been performed with the original 5-point scale data.

children $(P=0.044)$. The belief that regular fish consumption prolongs life differed between age classes. The oldest respondents ( $>55$ years) scored significantly lower than the youngest $(<25$ years) and the middle $(40-55$ years) age groups $(P=0.031)$. Subjects with higher education (after 18 years) scored higher $(P<0.001)$ on the belief that regular fish consumption stimulates brain development. Income level and family size did not have any significant impact on the health benefit beliefs from regular fish consumption.

\section{Fish nutrient content beliefs}

Table 2 shows that respondents' strongest belief was about the presence of vitamin D in fish. Surprisingly, $45.5 \%$ of the subjects claimed that fish contains dietary fibre, whereas less than one-third of respondents were aware of omega-3 fatty acids in fish. Almost $62.0 \%$ of the respondents in the case of omega-3 fatty acids and $42.0 \%$ in the case of vitamin D were unsure that fish contains those nutrients. Further analysis of the nutrient content perception yielded some significant differences between respondents. Women scored higher for the belief that fish contains dietary fibre $(P=0.035)$. With respects to age groups, the youngest respondents $(<25$ years) had a higher score $(P=0.034)$ for the belief that fish contains omega-3 fatty acids in comparison with consumers aged $>40$ years. Respondents without children tended to have a higher score for the belief that omega- 3 fatty acids are present in fish $(P=0.053)$. Lower scores for the presence of omega-3 fatty acids in fish were found for families with children younger than both 12 and 18 years. A significantly stronger belief that fish contains vitamin $\mathrm{D}(P=0.039)$ as well as omega-3 fatty acids $(P=0.034)$ was observed for the respondents who have higher education (after 18 years). In contrasts, subjects with lower education (below 18 years) tended to have a stronger belief that fish contains dietary fibre $(P=0.091)$. Income level and family size were not found to influence nutrient content beliefs in fish. Finally, heavy users had a stronger belief $(P=0.034)$ that fish contains vitamin $\mathrm{D}$ than did low users, whereas no differences with respect to omega-3 fatty acids and dietary fibre were detected between fish use levels.

\section{Fish contaminant content beliefs}

Respondents held the strongest beliefs that fish may contain heavy metals $(\mu=3.40)$, PCBs $(\mu=3.16)$ and dioxins ( $\mu=3.08$ ) as harmful substances. The lowest level of belief was noticed for the statement that fish contains colorants $(\mu=2.79)$. The average belief scores for harmful substances were lower than the belief scores for nutrients, which denotes a stronger belief in the presence of beneficial than harmful components. Men had a higher belief in the presence of PCBs $(P=0.045)$, and tended to believe more in the presence of heavy metals $(P=0.077)$ and colorants $(P=0.080)$ in fish. The youngest age group had higher scores for the presence of PCBs $(P=0.005)$, dioxins $(P=0.003)$ and colorants $(P=0.05)$. Respondents without children had a stronger belief that fish contains PCBs $(P=0.009)$, colorants $(P=0.002)$ and dioxins $(P=0.001)$ than did families with children. 
Respondents with higher education had a significantly stronger belief in the presence of heavy metals $(P=0.019)$ and PCBs $(P=0.040)$ in fish. Furthermore, they tended to have a stronger belief in the presence of dioxins $(P=0.090)$. Income level and family size did not influence the perception of harmful substances in fish. Low users held a stronger belief $(P=0.003)$ that fish contains heavy metals than did heavy users.

\section{Perceived effect of nutrients}

A large majority of the subjects were aware that vitamin D and dietary fibre have a positive effect on human health (Table 3), although the latter is obviously not relevant when considering fish. Remarkably, only $30 \%$ of the respondents stated that omega- 3 fatty acids have a positive effect on human health. Women $(P=0.012)$ had a stronger belief that vitamin $D$ has a positive effect on health. In general, the younger the respondent, the better the acquired knowledge about the effect of nutrients. Younger respondents scored higher for the positive effect of vitamin D $(P=0.014)$ and dietary fibre $(P<0.001)$. A significantly stronger belief in the positive effect of vitamin $\mathrm{D}(P<0.001)$ and dietary fibre $(P<0.001)$ was also found among respondents who have higher education. The higher the income, the better the awareness of the positive effect of vitamin D $(P=0.013)$ on human health. Fish consumption level was not associated with the perceived effect of nutrients.

\section{Perceived effect of contaminants}

Most of the respondents believed that heavy metals (77.3\%), medicinal residues (76.3\%), pesticide and other chemical residues (83.1\%), PCBs (77.1\%) and dioxins (81.7\%) have a negative effect on human health (Table 3 ). As with perceived effects of nutrients, younger respondents were better aware of the negative effect of harmful substances. The youngest respondents $(<25$ years $)$ scored significantly higher for the negative effect of heavy metals $(P=0.036)$, medical residues $(P=0.05)$ and PCBs

Table 3 Consumer perception of effects, frequency distribution $(\%, n=429)$

\begin{tabular}{lrrrc}
\hline Item & Negative & Neutral & Positive & Don't know \\
\hline $\begin{array}{lrrr}\text { 'Effect of. .' } \\
\text { Vitamin D }\end{array}$ & 2.4 & 10.8 & 71.6 & 15.2 \\
Omega-3 fatty acids & 16.3 & 14.4 & 30.0 & 39.3 \\
(PUFA) & & & & \\
Dietary fibre & 3.3 & 9.8 & 70.3 & 16.5 \\
PCBs & 77.1 & 2.9 & 4.1 & 15.9 \\
Dioxins & 81.7 & 1.9 & 5.0 & 11.4 \\
Pesticide and other & 83.1 & 1.4 & 4.1 & 11.4 \\
chemical residues & & & & \\
Heavy metals & 77.3 & 2.6 & 5.0 & 15.1 \\
Medicinal residues & 76.3 & 5.0 & 4.1 & 14.6 \\
Colorants & 53.0 & 27.4 & 4.5 & 15.0 \\
\hline
\end{tabular}

PUFA - polyunsaturated fatty acids; PCBs - polychlorinated biphenyls.
$(P=0.04)$, as well as for the neutral effect of colorants $(P=0.004)$. Pesticide residues and dioxins were considered to have a negative effect, irrespective of consumer age. Respondents without children had a significantly stronger belief that heavy metals have a negative $(P=0.012)$ and that colorants have a neutral $(P<0.001)$ effect on health. Higher educated respondents were more aware of the negative effect of heavy metals $(P<0.001)$, medical residues $(P<0.001)$, pesticide residues $(P<0.001)$, PCBs $(P<0.001)$ and dioxins $(P=0.001)$ compared with lower educated consumers. Finally, more respondents with higher education $(P=0.001)$ believed that colorants have a neutral effect on health. The higher the income, the better the awareness of the negative effect of PCBs $(P=0.004)$ on human health. No significant impact of fish consumption level was noticed for the perception of contaminants' effects on human health.

\section{Discussion}

\section{General picture of individual differences in perception}

In general, women consume more fish, both at home and in restaurants. They hold stronger beliefs that fish is healthy and that regular fish consumption reduces risks of coronary heart disease. Additionally, women believe more strongly that fish contains nutrients. Women's stronger belief holds particularly for dietary fibre, which is a clear example of misperception. In contrast, men hold stronger beliefs that fish contains harmful substances. The youngest respondents $(<25$ years) consume fish least frequently, which corroborates with their weaker belief that fish is healthy and safe. On the other hand, they have the best knowledge about the nutrients in fish, particularly omega3 fatty acids. The youngest respondents have also the strongest belief that fish may contain harmful substances. Furthermore, younger consumers are better aware of the positive effects of nutrients and the negative effects of contaminants. Older consumers ( $>40$ years) consume fish most frequently. They hold the strongest belief that fish is healthy, although they have the weakest knowledge that fish contains omega-3 fatty acids. It should be noted that today's consumers in the $>40$ years age group have typically been educated with product-based nutrition information like 'eating fish is healthy', whereas today's adolescents have rather been educated with nutrientbased messages like 'fish contains omega-3 fatty acids, which is beneficial for human health'. The findings of our study suggest that this difference in the scope of public health and nutrition education is reflected in consumers' beliefs about fish. Tradition (Catholic religious habits of eating fish on Friday) and economic factors partly explain age-dependent differences in fish consumption. Nevertheless, a hypothesis from this study is that differences in consumer understanding and effectiveness of the older 'food product-based' approach to nutrition education, 
versus the current 'nutrient-based' approach, contribute to the explanation of the fish consumption gap between the young and elderly population.

Other individual differences are that respondents with children hold stronger beliefs that fish is healthy and that regular fish consumption reduces risks of coronary heart disease. In contrast, families without children have weaker beliefs that fish contains nutrients, particularly omega-3 fatty acids. They also hold weaker beliefs about the possible presence of harmful substances in fish. Lower educated respondents believe more strongly that fish is healthy. However, they have a poorer knowledge of fish, which is exemplified by their stronger belief that fish contains dietary fibre and weaker belief that fish contains omega-3 fatty acids and vitamin D. Respondents with a higher education have a stronger belief that fish may contain harmful substances.

\section{Beneficial effects of fish: consumers' beliefs versus scientific evidence}

Consumers believe with reason that fish is healthy and nutritious, in view of its content of proteins and essential micronutrients (e.g. vitamin D) and of the fact that fish and other marine foods are a unique source of long-chain $n-3$ PUFA. Surprisingly, only $17.1 \%$ of the respondents really knew that fish contains no dietary fibre. It is assumed that this misunderstanding results from the 'fibrous' texture of the flesh of some fish species, which however has nothing to do with dietary fibre. Knowledge of the vitamin D content in fish is better, but the results with respect to omega-3 fatty acids show that most people are not fully aware of the nutrient content of fish. This shows that there is a definite need to inform people about the nutritional value and benefit of fish.

A majority of consumers score neutral on the belief that fish is safe. Fish safety is difficult to confirm from a scientific point of view, given the large number of quite divergent concentrations for contaminants in fish found in the literature and the scientific debate and uncertainty about the effects of contaminants in fish on human health. In cases where science is inconclusive, it should come as no surprise that consumers score neutral.

Thanks to the content of $n-3$ PUFA in marine food products, regular fish consumption reduces risk for coronary heart diseases, which is also the strongest health benefit belief of consumers. Scientific data indicate that regular fish consumption and the intake of $n-3$ PUFA play an important role in the primary and secondary prevention of coronary heart disease and stroke ${ }^{3,4,12,13,27,28}$. Possible mechanisms involved in this protective action of $n-3$ PUFA relate mainly to their antiarrhythmic, antithrombotic, anti-inflammatory and antiatherogenic effects ${ }^{3,12,13} \cdot n-3$ PUFA also have a beneficial effect on endothelial function and the immune system, and can help in lowering blood pressure in hypertensive individuals ${ }^{12}$
People have some belief that regular fish consumption reduces risk for some types of cancer, although this belief is much weaker than the belief in risk reduction for coronary heart disease. The potential protective effect of regular fish consumption vis-à-vis the development of malignant tumours is currently somewhat controversial and subject to further debate. On one hand, there is increasing evidence from animal and in vitro studies that $n-3$ PUFA in fatty fish and fish oil can inhibit specific steps in the carcinogenesis process ${ }^{4,29,30}$. Some ecological epidemiological studies have shown that a high per capita fish consumption is correlated with a lower incidence of some types of cancer in the population ${ }^{31,32}$. On the other hand, contamination of fish with dioxins, chemical residues or heavy metals possibly stimulates carcinogenesis $^{12}$. The fact that science is inconclusive in this matter is reflected to some extent in consumers' belief scores.

Regular fish consumption can improve the development of bones, owing to the content of vitamin D in fish. In contrast with scientific evidence, this fact is believed only by one-third of consumers. Vitamin D is essential for proper bone mineralisation; its intake is especially important for young children to prevent rickets and for elderly people, who are at risk for osteoporosis and osteomalacia. Apart from fish, there are relatively few food items e.g. eggs, liver and butter that naturally contain nutritionally significant quantities of vitamin $\mathrm{D}^{2}$.

The presence of DHA may be one of the probable causes that regular fish consumption stimulates brain development. This health benefit is believed only by slightly over one-third of the respondents. It has been known since the 1960s that DHA is one of the major components of the grey matter of the nervous system (brain) and the phospholipids of the retina of the human eye (vision) ${ }^{3}$. It appears to play a vital role in the development of these organs and systems. Therefore, the maintenance of an adequate level of DHA in both the brain and the retina is important for proper functioning of the nervous system and visual functions ${ }^{33,34}$.

Today it is generally accepted that fish is an important component of a healthy and balanced omnivorous human diet, seeing its nutritious benefits. Such a healthy diet will benefit human health, strength and life expectancy. In this context, it is noteworthy that the lay or popular statements relating to health benefits ('prolongs people's life', 'makes people strong' and 'makes people smart') received significantly lower belief scores than the more scientific formulation of the belief statements. This finding suggests that communication messages with a clear scientific base and formulation have a higher potential effectiveness (higher belief and plausibility) than do lay or vulgarised slogans. Further research should confirm this issue of effectiveness depending on the baseline formulation of public health and nutrition information messages. 


\section{Risks offish: consumers' beliefs versus scientific evidence}

The release of toxic chemicals into the environment leads to the contamination of surface water and sediments of streams, rivers and lakes. Fat-soluble contaminants concentrate in the fatty tissues of fish by bioaccumulation and biomagnification processes. Therefore high levels of environmental contaminants may be stored in fatty tissues of fish ${ }^{12,13,35}$. Examples are PCBs, dioxins, brominated flame retardants, organochlorine pesticides and heavy metals (mercury, arsenic, cadmium). On the other hand, residues of colorants and antibiotics (medicinal residues) are contaminants of concern in farm-raised fish and shellfish $^{36,37}$. With regard to fish and other marine organisms that enter the food chain, a large number of quite divergent concentrations for these harmful substances can be found in the literature ${ }^{38,39}$. Nevertheless, fish consumption is considered as a major source of human exposure to the above-mentioned environmental contaminants ${ }^{35,40}$.

Potential health risks related to fish consumption may be due to the contamination of fish with carcinogenic and non-carcinogenic environmental contaminants. Dioxins for example have a broad series of toxic and biochemical effects, mainly related to the immune and reproductive systems, and some of them are classified as known carcinogens $^{35}$. Mercury has been shown to produce a variety of toxic and teratogenic effects in humans. Moreover, the hypothesis arises that methyl mercury can diminish the beneficial health effect of the $n-3$ PUFA in fish $^{12}$

The results of the consumer study show that the best known of the contaminants that can be present in fish are heavy metals, PCBs and dioxins. It is remarkable to see that the belief that fish contains heavy metals has a higher score than the belief that fish contains omega- 3 fatty acids. This denotes that consumer awareness of these safety risks is higher than their awareness of a definite health benefit. Furthermore, consumers' awareness of the negative effect of harmful substances is higher than their awareness of the positive effect of nutrients. These findings exemplify the alleged conflict model in consumers' minds, and it shows that there is a lot that must be done about the image of fish for human consumption. The question is whether 'safety first' and safety-related risk information intrinsically prevail over health benefit information in consumers' decision-making, or whether 'safety' prevails only because 'health' is already taken for granted (most strongly believed in) in this specific case of fish.

\section{Conclusions}

Gaps between consumer perception and scientific evidence related to fish have been discovered, in particular with respect to the nutrient content and health-promoting effects of fish. Despite conclusive evidence about the content and positive effect of omega3 fatty acids in fish, related consumer awareness and beliefs are rather poor, especially among consumers with lower education level. Younger consumers are better aware that fish contains beneficial nutrients and harmful substances. They have better knowledge that harmful substances have a negative effect, but their knowledge of the positive impact of omega-3 fatty acids does not differ from that of older consumers. Higher awareness of conflicting information among young consumers can be a reason to eat less fish. In general, the healthy image of fish prevails over its image of being potentially unsafe. Nevertheless, $43 \%$ of the respondents do not eat fish at least once a week. This study exemplifies the need for nutrition education and more effective communication about fish to the broader public. Fish is one of the few food products where consumers will have to balance clear health benefits against potential safety risks. Hence, further research is needed about the impact of conflicting information and communication on consumer decisionmaking. Further research is also recommended to strengthen scientific evidence about benefits and risks from fish consumption. More specifically, insight into balancing nutrient intake versus harmful substance exposure from fish consumption is needed in order to issue appropriate dietary recommendations and public health information.

\section{Acknowledgements}

The authors gratefully acknowledge financial support from the Belgian Science Policy through SPSD II project $\mathrm{CP} / 02 / 56$. The consumer perception part of the work was partially performed within the Integrated Research Project SEAFOODplus, contract no. FOOD-CT-2004-506359. Partial financing of the work by the European Union is gratefully acknowledged.

\section{References}

1 Dias MG, Sanchez MV, Bartolot H, Oliviera L. Vitamin content of fish and fish product consumed in Portugal. Electronic Journal of Environmental, Agricultural and Food Chemistry 2003; 2(4).

2 Bender DA. The vitamins. In: Gibney MJ, Vorster HH, Kok FJ, eds. Introduction to Human Nutrition. Oxford: Blackwell Science Ltd, 2002; 125-76.

3 Sidhu KS. Health benefits and potential risks related to consumption of fish or fish oil. Regulatory Toxicology and Pharmacology 2003; 38: 336-44.

4 Hoge Gezondheidsraad. Vis en gezondheid bij volwassenen [Fish and Health among Adults]. Report D/2004/7795/3. Brussels: FOD Volksgezondheid, 2004.

5 Brunsø K. Consumer research on fish in Europe. In: Luten JB, Oehlenschlager J, Olafsdottir G, eds. Quality of Fish from Catch to Consumer: Labelling, Monitoring and Traceability. Wageningen: Wageningen Academic Publishers, 2003; 335-44.

6 Gross T. Consumer attitudes towards health and food safety. In: Luten JB, Oehlenschlager J, Olafsdottir G, eds. Quality 
of Fish from Catch to Consumer: Labelling, Monitoring and Traceability. Wageningen: Wageningen Academic Publishers, 2003; 401-11.

7 Scientific Advisory Committee on Nutrition. Committee on Toxicity of Chemicals in Food. Advice on Fish Consumption: Benefits and Risks. London: The Stationery Office, 2004.

8 Welch AA, Zavitsanos X, Tumino R, Galasso R, Bueno-deMesquita HB, Ocké MC, et al. Variability of fish consumption within the 10 European countries participating in the European investigation into Cancer and Nutrition (EPIC) study. Public Health Nutrition 2002; 5: 1273-85.

9 Leek S, Maddock S, Foxall G, Lund E, Amiano P, Dorronsoro $\mathrm{M}$, et al. Determinants of fish consumption. British Food Journal 2000; 102: 18-39.

10 Trondsen T, Scholderer J, Lund E, Eggen AE. Perceived barriers to consumption of fish among Norwegian women. Appetite 2003; 41(3): 301-14.

11 Verbeke W, Vackier I. Individual determinants of fish consumption in Belgium: application of the theory of planned behaviour. Appetite 2005; 44(1): 67-82.

12 Kris-Etherton PM, Harris WS, Appel LJ. Fish consumption, fish oil, omega-3 fatty acids, and cardiovascular disease. Circulation 2002; 106: 2747-57.

13 Kris-Etherton PM, Harris WS, Appel LJ. Omega-3 fatty acids and cardiovascular disease - new recommendations from the American Heart Association. Arteriosclerosis, Thrombosis, and Vascular Biology 2003; 23: 151-2.

14 Vrijens B, De Henauw S, Dewettinck K, Talloen W, Goeyens L, De Backer G, et al. Probabilistic intake assessment and body burden estimation of dioxin-like substances in background conditions and during a short food contamination episode. Food Additives and Contaminants 2002; 19: 687-700.

15 Frewer LJ, Howard C, Hedderley D, Shepherd R. The elaboration likelihood model and communication about food risks. Risk Analysis 1997; 17: 759-70.

16 Burger J, McDermott MH, Chess C, Bochenek E, Perez-Lugo $\mathrm{M}$, Pflugh KK. Evaluating risk communication about fish consumption advisories: efficacy of a brochure versus a classroom lesson in Spanish and English. Risk Analysis 2003; 23: 791-803.

17 Alhakami A, Slovic P. A psychological study of the inverse relationship between perceived risk and perceived benefit. Risk Analysis 1994; 14: 1085-96.

18 Siegrist M, Cvetkovich G. Better negative than positive? Evidence of a bias for negative information about possible health dangers. Risk Analysis 2001; 21: 199-206.

19 Carson C, Hassel C. Educating high risk Minnesotans about dietary fats, blood cholesterol and heart diseases. Journal of the American Dietetic Association 1994; 94: 659-60.

20 Robenstein R, Thurman W. Health risk and the demand for red meat: evidence from futures markets. Review of Agricultural Economics 1996; 18: 629-41.

21 Kinnucan $\mathrm{H}$, Xiao H, Hsia CH, Jackson J. Effect of health information and generic advertising on US meat demand. American Journal of Agricultural Economics 1997; 79: $13-23$.

22 Mizerski RW. An attribution explanation of the disproportionate influence of unfavorable information. Journal of Consumer Research 1982; 9: 301-10.

23 Verbeke W, Ward RW. A fresh meat almost ideal demand system incorporating negative TV press and advertising impact. Agricultural Economics 2001; 25: 359-74.

24 National Institute of Statistics (NIS). Population Census Data January 1, 2003. Brussels: NIS, 2002.

25 Wetenschappelijk Instituut voor Volksgezondheid (WIV). Health Interview Survey. Brussels: WIV, 2001.

26 Inra Marketing Research. Fish Campaign Evaluation 'Fish or fish' Results after One Year of Campaigning. Brussels: Inra Marketing Research, 2003.

27 de Deckere EAM, Korver O, Verschuren PM, Katan MB. Health aspects of fish and $n-3$ polyunsaturated fatty acids from plant and marine origin. European Journal of Clinical Nutrition 1998; 52: 749-53.

28 Whelton SP, He J, Whelton PK, Munter P. Meta-analysis of observational studies on fish intake and coronary heart disease. American Journal of Cardiology 2004; 93: 1119-23.

29 Terry PD, Rohan TE, Wolk L. Intakes of fish and marine fatty acids and the risks of cancers of the breast and prostate and of other hormone-related cancers: a review of the epidemiologic evidence. American Journal of Clinical Nutrition 2003; 77: 532-43.

30 Larsson SC, Kumlin M, Ingelman-Sundberg M, Wolk A. Dietary long-chain $n-3$ fatty acids for the prevention of cancer: a review of potential mechanisms. American Journal of Clinical Nutrition 2004; 79: 935-45.

31 Caygill CPJ, Charlett A, Hill MJ. Fat, fish, fish oil and cancer. British Journal of Cancer 1996; 74: 159-64.

32 Sasaki S, Horacsek M, Kesteloot H. An ecological study of the relationship between dietary-fat intake and breast-cancer mortality. Preventive Medicine 1993; 22: 187-202.

33 Salem NJ, Pawlosky RJ. Docosahexaenoic acid is an essential nutrient in the nervous system. Journal of Nutritional Science and Vitaminology 1992; 38: 153-6.

34 Tanaka Y, Funada T, Hirano J, Hashizume R. Triacylglycerol specificity of Candida cylindracea lipase: effect of docosahexaenoic acid on resistance of triacylglycerol to lipase. Journal of the American Oil Chemists' Society 1993; 70: $1031-4$.

35 Karl H, Ruoff U, Bluthgen A. Levels of dioxins in fish and fishery products on the German market. Chemosphere 2002; 49: $765-73$

36 European Commission. Opinion of the Scientific Committee on Animal Nutrition on the Use of Canthaxanthin in Feedingstuffs for Salmon and Trout, Laying Hens, and Other Poultry. Brussels: European Commission, Health \& Consumer Protection Directorate-General, 2002; 1-29.

37 Alderman DJ, Hastings TS. Antibiotic use in aquaculture: development of antibiotic resistance - potential for consumers' health risks. International Journal of Food Science and Technology 1998; 33: 139-55.

38 Leonards PE, Lohman M, de Wit MM, Booy G, Brandsma SH, de Boer J. Actuele situatie van gechloreerde dioxines, furanen en polychloorbifenylen in visserij-producten: Quick- en Full-Scan. Report C034/00. IJmuiden: RIVO, 2002.

39 European Commission. Assessment of Dietary Intake of Dioxins and Related PCBs by the Population of EU Members States. Scoop Report. Brussels: European Commission, Directorate-General Health and Consumer Protection, 2000.

40 Karl H, Kuhlmann H, Ruoff U. Transfer of PCDDs and PCDFs into the edible parts of farmed rainbow trout, Oncorbynchus mykiss (Walbaum), via feed. Aquaculture Research 2003; 34: 1009-14. 